\title{
CONDITIONS FOR MEASURING SEISMIC SHOCKS AND THEIR ANALYSIS AND RESPONSE ON BUILDINGS AND INDUSTRIAL STRUCTURES
}

\author{
Stanislav Ziaran ${ }^{1}$, Milos Musil ${ }^{1}$ and Michal Cekan ${ }^{1}$ \\ ${ }^{1}$ Faculty of Mechanical Engineering, Slovak University of Technology in Bratislava, Nam. slobody \\ 17, 81231 Bratislava, Slovakia \\ e-mail: stanislav.ziaran@stuba.sk,milos.musil@stuba.sk,michal.cekan@stuba.sk
}

Keywords: Seismic shock, FFT analysis, buildings, industrial structure, integrity, resonance

\begin{abstract}
The goal of this contribution is to define the conditions and basic principles for measuring seismic loads generated by seismic shocks, process and analyze the measured response of seismic (low frequency mechanical vibration) on buildings and industrial structures and to develop a methodology for measuring on a specific structure. The conditions and basic principles for measuring can be applied for different kinds of seismic sources of excitation such as: explosions, wind, random excitation from local transportation, periodic excitation from large rotating and/or machines with reciprocating motion, metal forming processes such as forging, shearing and stamping, chemical reactions, construction and earth moving work, earthquakes and other strong deterministic and random energy sources caused by human activities. All of which negatively affect the integrity of buildings and industrial structures as well as the environment of those who live or work in such conditions. In evaluating the effects of such seismic shocks (vibration) on buildings and industrial structures, the response of these structures and the possible negative impact on them is performed. The contribution includes the appropriate analytical methods where the frequency, duration of, and amplitude is definable as well as the processing and verification of methodology and preparation of measurements, optimal location of measuring points, how to attach the sensors, the measurement equipments used, measured variables and procedure are also given. For the detection of a seismic shock resulting from an explosion the FFT analysis and modal analysis, in the frequency domain, is used and the signal was acquired and evaluated also in the time domain. In the conclusions the measured results of a seismic shock caused by blasting in a nearby quarry and its effect on a nearby structure (house) is evaluated. The response on the house, including the natural frequency and possible fatigue damage is also assessed.
\end{abstract}




\section{INTRODUCTION}

The response of buildings and industrial structures on seismic excitation depends on the type of excitation, because there are differences between earthquakes and mechanical vibrations (further just vibration) and/or shock (dynamic loading) resulting from human activities which effect the conditions of the measured data. Sources of earthquakes are dimensionally large and much deeper than most vibration sources caused by human activity. Earthquakes cause damage over large distances, are characterized by a much larger flow of seismic energy, duration and different types of seismic wave propagation. Therefore, for the same evaluating parameter, for example, the peak value of the measured objects element velocity, the effects on buildings and industrial structures vary. In this respect, seismic measurements are affected by the source of the shock (vibration) and thus its frequency, duration and amplitude, where the low frequency vibration caused by an earthquake, wind, explosions [1], aerodynamic impact, machines installed in buildings or industrial structures and/or in the vicinity of these structures $[2,3,4]$, technological processes such as forging, shearing and forming [5], chemical processes [6], transportation, construction activity and other sources of unwanted seismic excitation, must be considered. The effects of seismic events on buildings and industrial structures can by evaluated analytically. In such an analysis the resonant frequency of the basic construction and its parts must be considered, for example, for buildings it is the resonance of the walls, floors and windows. Also of importance is the modal damping characteristics of the structure and its parts, type of construction, its state and material properties including its nonlinearity of the amplitude at response of the monitored construction and finally the spectral properties of the construction such as the mode shapes but also the spectral of the seismic excitation. In such an evaluation of the procedure, source of seismic excitation, transfer path and transfer function, exposition of the construction and its response must also be taken into consideration.

\section{MEASUREMENT CONDITIONS IN THE SEISMIC EXPOSITION OF THE STRUCTURES}

In assessing the effects of seismic shock and/or low frequency vibration on buildings and industrial structures, rules dictate that the following be performed before measurement:

- technical assessment of the monitored construction, documentation of its important structural nodes, mainly its foundation, characteristic dimensions, finishing method and construction material, study of available documentation and defining procedures for the solution of the problem;

- analysis of the structures current state and its documentation;

- implementing the plan for experimental testing corresponding to the source of the seismic action, transfer path and position of the monitored structure in situ with respect to the source of the dynamic loading;

- evaluation of the terrain in the path of the seismic wave, mainly in terms of the transverse relief in the direction of the seismic wave propagation (For example, over a plane, in a valley, over hills) where deflection, interference or dispersion of the energy of the seismic wave can occur;

- determination of the measurement areas in the building and/or the industrial structure in terms of the location of the explosion (see fig. 1); 
- measurement of seismic shock (vibration) and its transfer from the source of the natural areas to the object being measured, including the FFT analysis and time domain;

- measurement and vibration analysis of secondary vibration (background analysis) and its evaluation;

- evaluation of the effects of the seismic shock on the measured structure, for example, in terms of standards ISO 4866 [8], scientific literature [9. 10, 11] and current experience of the evaluators.

\subsection{Quantification of the Seismic Excitation Source}

Seismic loading (vibration, shocks) can be classified as deterministic or random loading. For example, a seismic shock generated by an explosion, which is the case in this paper for analysis, is considered to be between deterministic and non-periodic dynamic loading.

The duration of the dynamic excitation force is an important parameter and the response of such loading can considered continuous or transient. The type of response is given by the relationship between the time constant with the response of the structure and force action. The time constant of the resonance response for resonance (indicated by index $\mathrm{r}$ ), $\tau_{\mathrm{r}}$, in seconds, is given by [8]:

$$
\tau_{\mathrm{r}}=\frac{1}{2 \pi \xi_{\mathrm{r}} f_{\mathrm{r}}}
$$

where $\xi_{\mathrm{r}}$ represents the damping effects and depends on the type of excitation (linear or nonlinear);

$f_{\mathrm{r}}$ is the resonant frequency.

In this way two scenarios can be defined (regardless whether the excitation is deterministic or random), and that is:

- continuous, if the structure is acted on by a continuous force effect for more than $5 \tau_{\mathrm{r}}$, the vibration is considered to be continuous. For example, a series of blasts with a high number of individual explosions;

- transient, if the action of force is shorter than $5 \tau_{\mathrm{r}}$, the response is considered to be transient. For example, one explosion or a series of blasts with a small number of individual explosions.

Demolition work, when a series of blast is used, can be considered as a transient or continuous case that is dependent on the length of the resonance response. In the given case, the response generated by one explosion can be considered as transient.

The frequency interval (range) of vibration, which is the case in this contribution, depends on the distribution of the spectra in the frequency range of excitation and from the mechanical response of the structure. This emphasizes the limits of the spectra's contents as one of the most important properties of input vibration (shock). In the interest of simplification, the frequency range is taken to be from $0.1 \mathrm{~Hz}$ to $500 \mathrm{~Hz}$, which covers the response for a wide variability in buildings and industrial structures and their structural elements excited by natural sources (winds and earthquakes) and human activities (construction work, mechanical and chemical industries, demolition work, transportation of heavy vehicles, etc...), in the 
excitation of internal mechanical equipment, measurement of higher frequencies may be required [2].

More so, damage to buildings and industrial structures caused by human activity occur in the frequency range from $1 \mathrm{~Hz}$ to $150 \mathrm{~Hz}$. Natural sources, such as earthquakes, typically have intensive energy, which has damaging effects at lower frequencies (from $0.1 \mathrm{~Hz}$ to $30 \mathrm{~Hz}$ ). Excitations caused by wind have significant energy in the frequency range of $0.1 \mathrm{~Hz}$ to $2 \mathrm{~Hz}$. Apart from these realities, for the given situation (nearby explosion) the frequency range of measurement is defined up to $200 \mathrm{~Hz}$.

The level of vibration velocity, in the range which is of interest, depends on the frequency and the value of their velocity is from a few millimeters per second to as much as a few hundred millimeters per second. For more detailed information regarding vibration velocity strength of vibration, see [7].

\subsection{Quantification of Buildings and Industrial Structures}

The reaction of building and industrial structures (and their components) on seismic excitation depends on the frequency characteristic (on the natural frequency, and natural modes of vibration and modal damping), as well as the contents of the excitation spectra. Practice dictates that the cumulative effects are taken into consideration, especially for high levels of response and long exposition time, where fatigue damage is possible $[2,5]$.

The basic natural frequencies of a structure or its parts impact their response. Therefore it is necessary to know the methods in evaluating vibration, which are used in the assessment of structures. It can consist of the spectral analysis with low level response on the surrounding excitations or the use of exciters $[8,9]$.

Experimental studies [9] have shown a range of basic frequencies from $4 \mathrm{~Hz}$ to $15 \mathrm{~Hz}$ for transverse vibration (shear loading) on low structures (from $3 \mathrm{~m}$ to $12 \mathrm{~m} \mathrm{high}$ ). The damping properties are typically dependent on the amplitude. The building in this paper belongs to this category of structures, therefore it is expected to obtain the natural frequencies in this range (fig. 1).
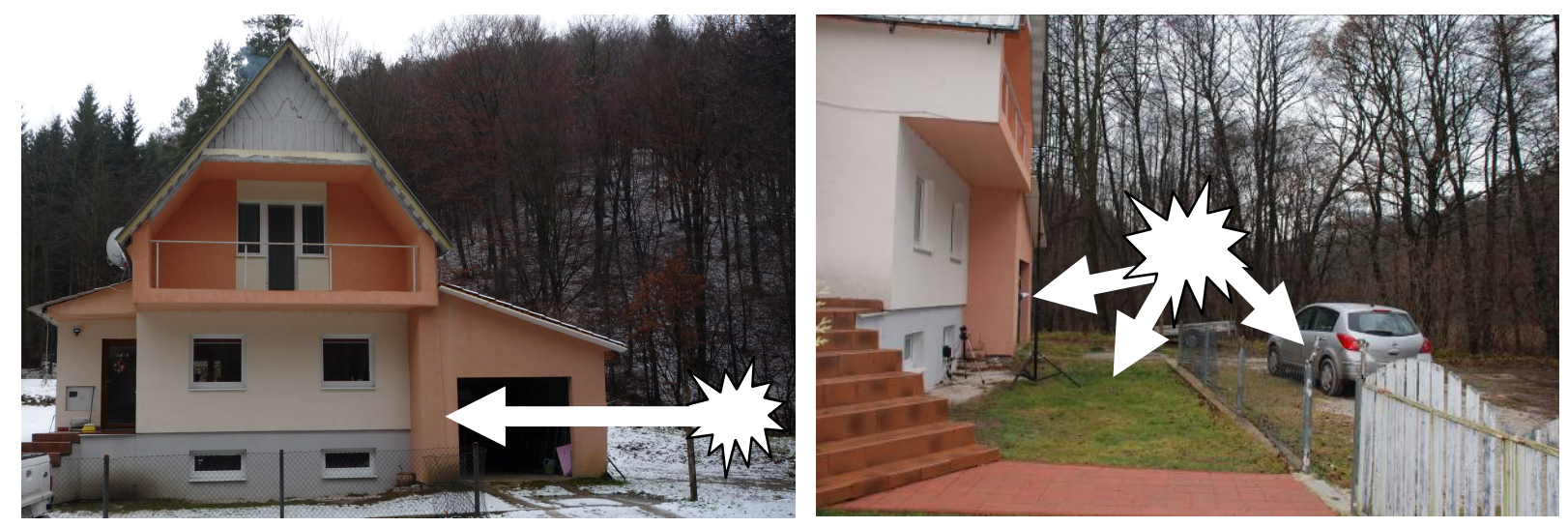

Figure 1: Measured object (left); location of explosion $1250 \mathrm{~m}$ away from the object (right)

Vibrations propagating through the ground can have a wavelength from a few meters to a few hundred meters. The response of short wavelength vibrations is complex and the foundation of buildings or industrial structures can act as a filter. Smaller structures, such as homes and cottages, typically have foundations that are dimensionally smaller than the basic 
wavelength of all seismic sources except for sources with the highest frequencies [8], which have an effect on the dynamic loading of the structures.

Evaluating the interaction effects of the floor is sometimes done while vibration induced by human activity. Evaluation conditions are defined such as: the velocity of the transverse wavelength (shear effects on the structure) or dynamic module of elasticity from an appropriate volume of earth. Foundations on poor ground can cause the foundation to sink or loose stability. The risk of such effects is a function of the granular size of earth, its homogeneity, compaction, moisture level, internal stress state, as well as the peak value of multidirectional acceleration and duration of the grounds excitation. Especially sensitive ground are free, loose, sand with high water content, which for extreme cases can become quicksand $[3,4]$. The transverse relief of the terrain should also be taken into consideration, since it transmits the seismic waves. In flat terrain the area dispersion of seismic energy occurs. For valleys this dispersion is minimal, and the size of the propagating seismic energy rebounds off of steep slopes in the valley and is affected by wave interference.

The measured object is built on rigid ground, which simplifies the measurement since a single sensor can be used to measure the horizontal direction of the transmitted vibration. On the other hand, the object is located in a narrow valley, where the dispersion of seismic energy is minimized from the source of the dynamic excitation generated by human activities such as a blast in a quarry.

\section{METHODOLOGY OF THE EXPERIMENT}

The goal of the experimental tests is to determine the effects of seismic shocks (mechanical impulse, random or periodic vibration) and the possible damage to buildings and/or industrial structures, systems they may cause and the effects on human beings in the area of these objects with respect to their comfort and disturbance $[12,13,16]$. In order to realize such a test it is needed to:

- determine the location of the monitored structure with respect to the source of the seismic shock, if it is known (fig. 2 top);

- appropriately select three (or in some cases two) measurement areas, one in the horizontal plane and two perpendicular to each other in the vertical plane on ground floors. In the case that the object is placed at a known location to the source of the seismic shock, two measurement areas are sufficient, where the measurement in the horizontal direction coincides closely to the direction of the Rayleigh surface wave ray (fig. 2 bottom);

- measurement of the seismic shock (source of the dynamic load on the structure) including FFT analysis, during the exposition of the structure [7, 14];

- measurement and analysis of secondary vibrations (background) and their assessment;

- evaluate the source of the generated seismic shock (vibration) with respect to the important value, which can affect the measurements of the structure.

\subsection{Measurement Locations}

The structure measured is a three story house (see fig. 1), for which the first floor is built into a slope and used as a garage and basement. The location of the house with respect to the source of the explosion (seismic shock) is shown in fig. 2 top. The lower part in fig. 2 shows the floor plan of the house, measuring locations for the vertical and horizontal measurement 
directions, and location of the source (approximately $1250 \mathrm{~m}$ away). The plan also shows the direction of progression of the Rayleigh wave ray,
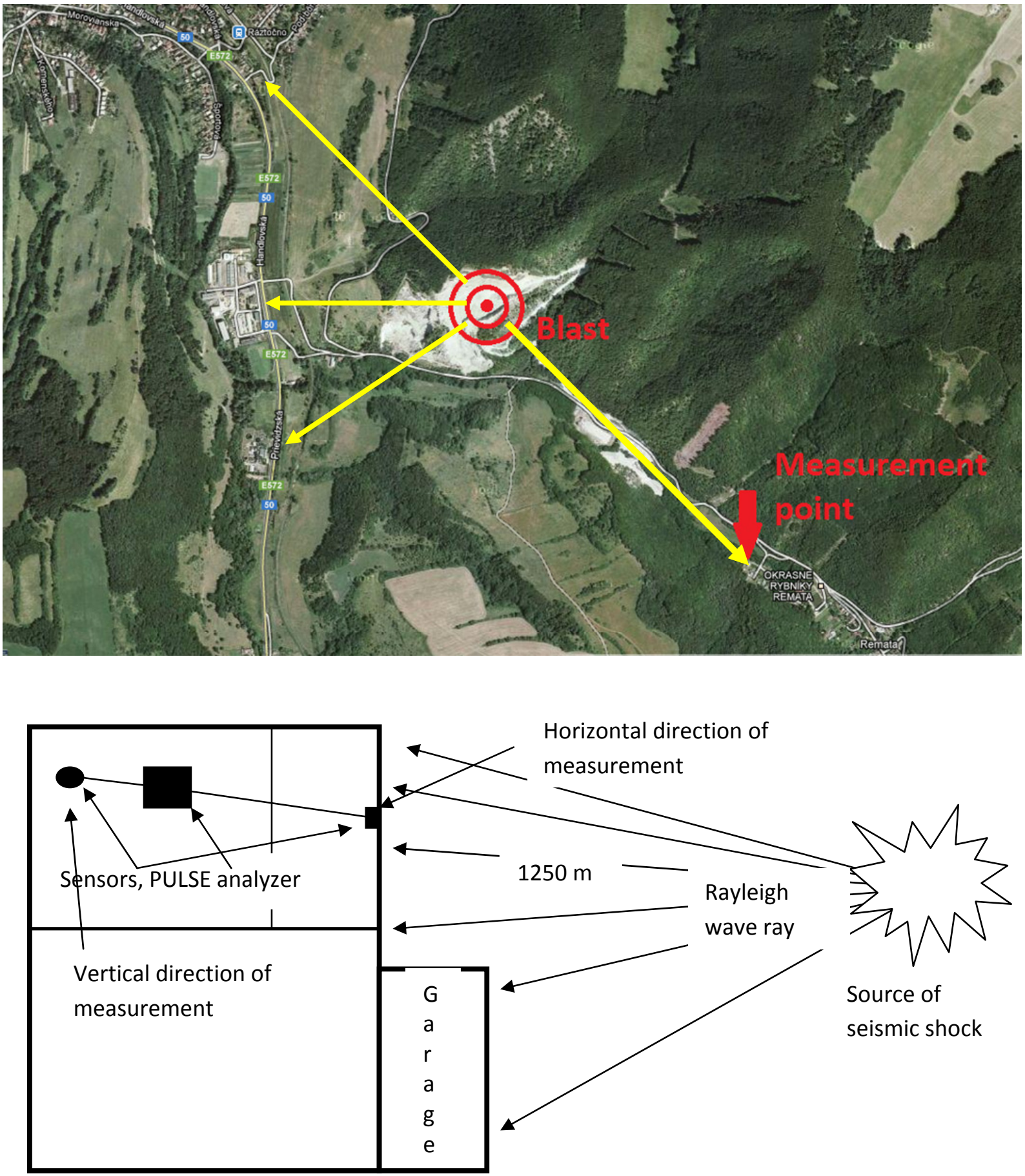

Figure 2: Source of the explosion with respect to the measured object (above), measurement points within the measured object (below)

\subsection{Measurement Equipment}

To measurement of the seismic shock (vibration) the PULSE Analyzer, Dyn-X, FFT, MI 3560-B-X10 made by Bruel \& Kjaer (fig. 3) was used. This analyzer represents an open system, which allows for new possibilities, more information and reliability in the 
measurement process, analysis, and evaluation. Part of this system is the piezoelectric accelerometer, microphone, display and memory module (laptop PC).

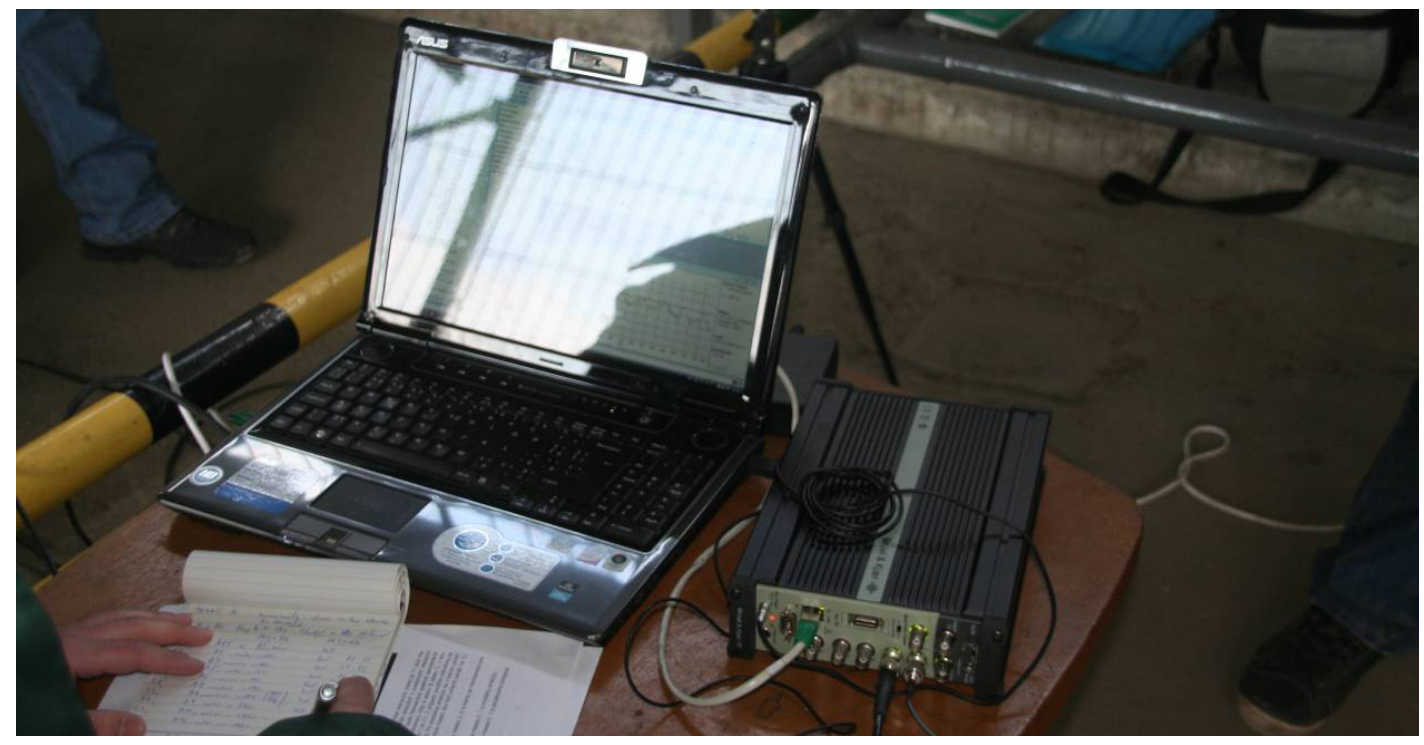

Figure 3: PULSE analyzer system with accessories

An appropriate aid in the measurement of kinematic parameters of seismic shocks (vibration) is a solid steel cylinder, which is used in the measurement of vertical vibrations in horizontal structural elements (fig. 4 left). This aid has three adjustable tips, which allow for the correct selection of sensor position even on an uneven base. For the measurement of kinematic parameters in the horizontal direction (vertical structural elements) various aids which rigidly attach to vertical (and perpendicular) load bearing walls (fig. 4 right). In the case that the location of the seismic event is known, horizontal measurements can be taken by only one sensor positioned such that its sensitive axis is positioned towards the seismic source. If the source is unknown, it is advised to use a tri-axial vibration sensor.

Sensor mounting on structural elements of the building must coincide with the ISO 5348 standard with respect to accelerometers [14]. The goal is to ensure that the sensor correctly reproduces the motion of the structural element or foundation without interfering with the response, thus the upper areas of the foundation were selected as a suitable element (fig. 4 right). It should be taken into consideration that any aid used in measuring kinematic parameters of seismic events in the horizontal direction are considered to be non acceptable.
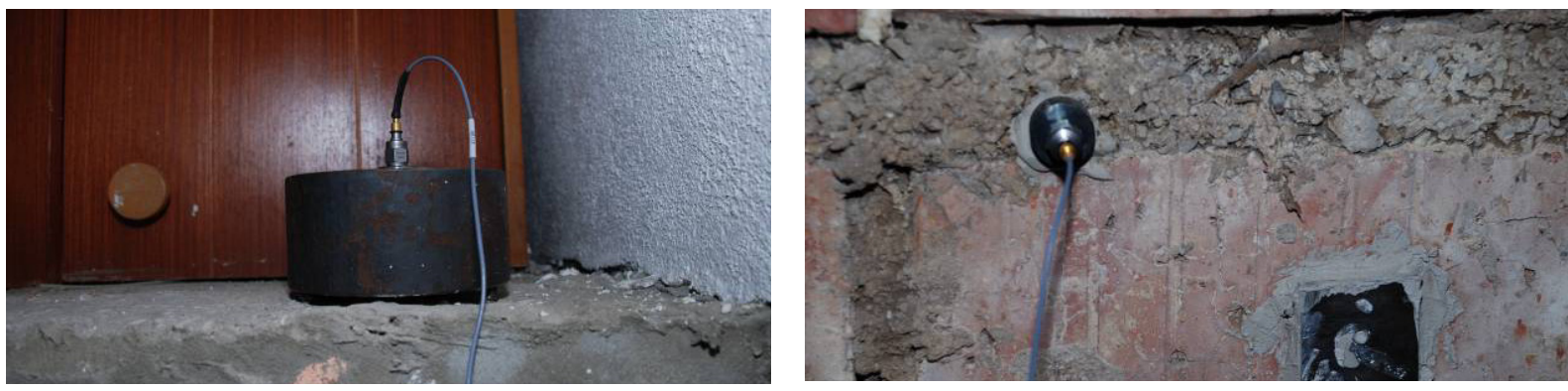

Figure 4: Measuring position and sensor placement for vertical vibrations (left); measuring position and sensor placement for horizontal vibrations (right) 


\subsection{Measured Parameters and Procedures}

The measurement device and its technical parameters must be calibrated before measuring any seismic event. Proper calibration and setup is very important in measuring short nonrepeating seismic events. Other than the frequency range, for the type of signal, it is also very important to select the appropriate type of averaging as well and number of averages per unit time as well as a suitable time window [15]. Definition of the measured parameter, such as the vibration velocity (strength of vibration) and other performance parameters must be done. For short non-repeatable seismic events caused by human activity (blasting in a quarry) it is indispensable to setup the time interval of the measurement such that the signal is measured before the event occurs (background signal), during the seismic event, and after the seismic event (background signal).the time interval of the seismic signal is the basis for determining the strength of the vibration, since this energy parameter is used to evaluate the effect of the seismic event on the structure. For example, basic parameters for vibration induced by blasting can be seen in tab. 1. Before and after the measurement of non-repeatable seismic events it is beneficial to measure any secondary vibrations from external and/or internal sources of dynamic loading.

\begin{tabular}{|c|c|c|c|c|c|c|}
\hline Force induced by vibration & $\begin{array}{c}\begin{array}{c}\text { Frequency } \\
\text { range }\end{array} \\
\mathrm{Hz}\end{array}$ & $\begin{array}{c}\text { Amplitude } \\
\text { range } \\
\mu \mathrm{m}\end{array}$ & $\begin{array}{c}\text { Segment } \\
\text { velocity } \\
\text { range } \\
\mathrm{mm} / \mathrm{s}\end{array}$ & $\begin{array}{c}\text { Segment } \\
\text { acceleration } \\
\text { range } \\
\mathrm{m} / \mathrm{s}^{2}\end{array}$ & $\begin{array}{c}\text { Time } \\
\text { characteristic }\end{array}$ & $\begin{array}{c}\text { Measured } \\
\text { variable }\end{array}$ \\
\hline $\begin{array}{l}\text { Vibration from blasting, } \\
\text { propagated through ground }\end{array}$ & $1-300$ & $100-2500$ & $0,2-500$ & $0,02-50$ & $\mathrm{~T}$ & pvth \\
\hline $\begin{array}{l}\text { Key } \\
\quad \mathrm{C}=\text { continuous; } \mathrm{T}=\text { transi } \\
\text { NOTES: } \\
\text { 1. - The ranges are extreme b } \\
\text { 3). The extreme range in ampl } \\
\text { 2. - The frequencies reflect th } \\
\text { Its character is only for orienta } \\
\text { 3. - Vibration values in the gi } \\
\text { state and duration of expositio } \\
\text { building foundation for more } \\
\text { whose value reaches a few hu } \\
\text { in cases of sensitive industrial }\end{array}$ & $\begin{array}{l}\text { at; pvth = part } \\
\text { indicate valu } \\
\text { ude, deviation } \\
\text { response of } \\
\text { on. } \\
\text { en ranges can } \\
\text { but many na } \\
\text { lan a few mm } \\
\text { dred mm/s. Tl } \\
\text { ork procedur }\end{array}$ & $\begin{array}{l}\text { velocity tim } \\
\text { which can be } \\
\text { nd frequency } \\
\text { building and } \\
\text { the cause of } \\
\text { hal codes con } \\
\text { significant pc } \\
\text { level of vibra }\end{array}$ & $\begin{array}{l}\text { ory } \\
\text { tified fro } \\
\text { ot used to } \\
\text { tural segn } \\
\text { bance. } \mathrm{N} \\
\text { lity of da } \\
\text { elow hun }\end{array}$ & $\begin{array}{l}\text { perience and } \\
\text { ve the segme } \\
\text { with respect } \\
\text { hdard exists, } \\
\text { l effects of p } \\
\text { is related to } \\
\text { eeling (ISO 2 }\end{array}$ & $\begin{array}{l}\text { hich can be me } \\
\text { velocity and ac } \\
\text { individual typ } \\
\text { ich cover all b } \\
\mathrm{k} \text { value segmer } \\
\text { e peak value } \mathrm{s} \\
1-2[14]) \text { shou }\end{array}$ & $\begin{array}{l}\text { red (see note } \\
\text { eration. } \\
\text { of excitation. } \\
\text { ling changes, } \\
\text { locity of the } \\
\text { lent velocity, } \\
\text { e considered }\end{array}$ \\
\hline
\end{tabular}

Table 1: Basic parameters for blasting [8]

Throughout the measurements other variables are recorded that are essential to the frequency analysis, identification of measurement location and their corresponding frequency spectra, such as possible unique effects during measurements (random impacts and shocks caused by human activities in the surrounding areas). Such unique events, which can impact the correctness of the results, are an essential part of seismic measurements. By means of FFT analysis, the natural frequency of the measured building is determined.

Overall, six auto spectrum are recorded from the defined measurement locations by means of contact vibration sensors (accelerometers), and coincidentally, the time history can be saved in memory for both measurement locations. Two auto spectrum and time history represent the blast itself and the remaining secondary dynamic loading (background).

\section{EVALUATION OF SEISMIC SHOCKS AND DISCUSSION}

Seismic shocks are beneficial to evaluate with respect to the frequency distribution of the signal, which allows for the determination of the structures mode shapes as well as time 
history, which records the maximum amplitude of vibration velocity and is used also in the further laboratory processing of the signal.

The environment of the measured object was seismically quite which means that there were no other sources of dynamic loading, such as from transportation, industry or other human activities. The measured object is located in a quite valley of mountains, which the frequency analysis of the background proves (no secondary vibrations from external sources was measured).

\subsection{Frequency Analysis of Seismic Shocks}

The frequency analysis of secondary vibration (background) from either measurement locations clearly confirms that no significant source of dynamic loading existed internally or externally (fig. 5). Significant vibration amplitudes at higher frequencies are caused by human activities, who were dwelling within the home (owner, child, operators) but had little effect on the results. From the frequency analysis of the background and seismic excitation, it is possible to state that the structure is sensitive to internal vertical excitation (fig. 5 right), while the horizontal excitation is sensitive to the seismic event.
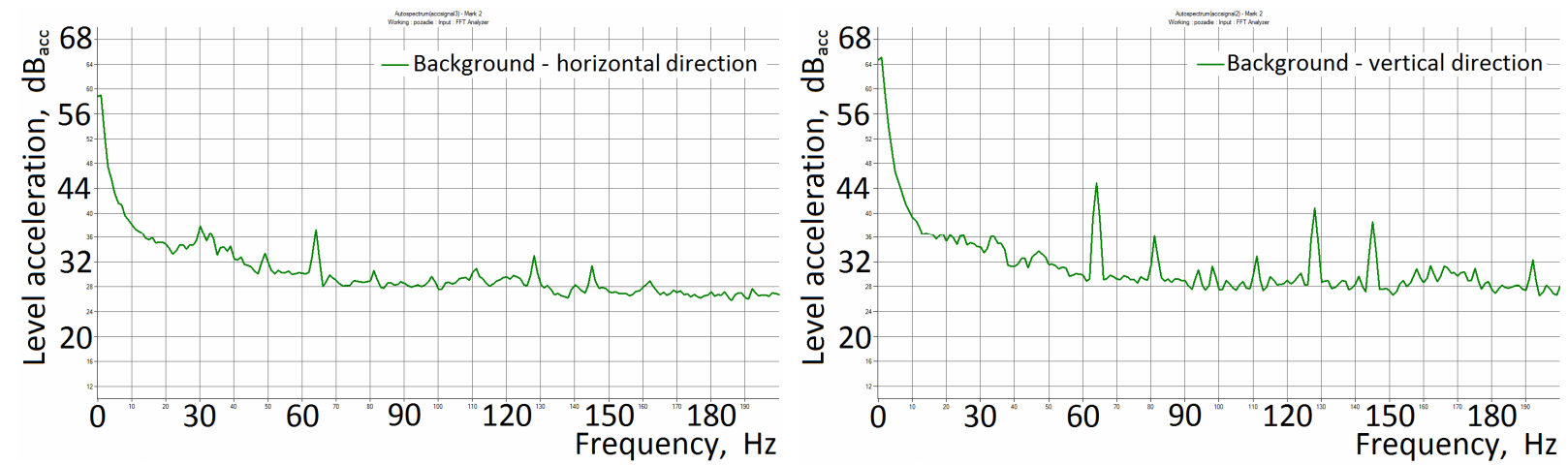

Figure 5: Frequency spectrum of the background in the horizontal direction (left) and vertical direction (right)
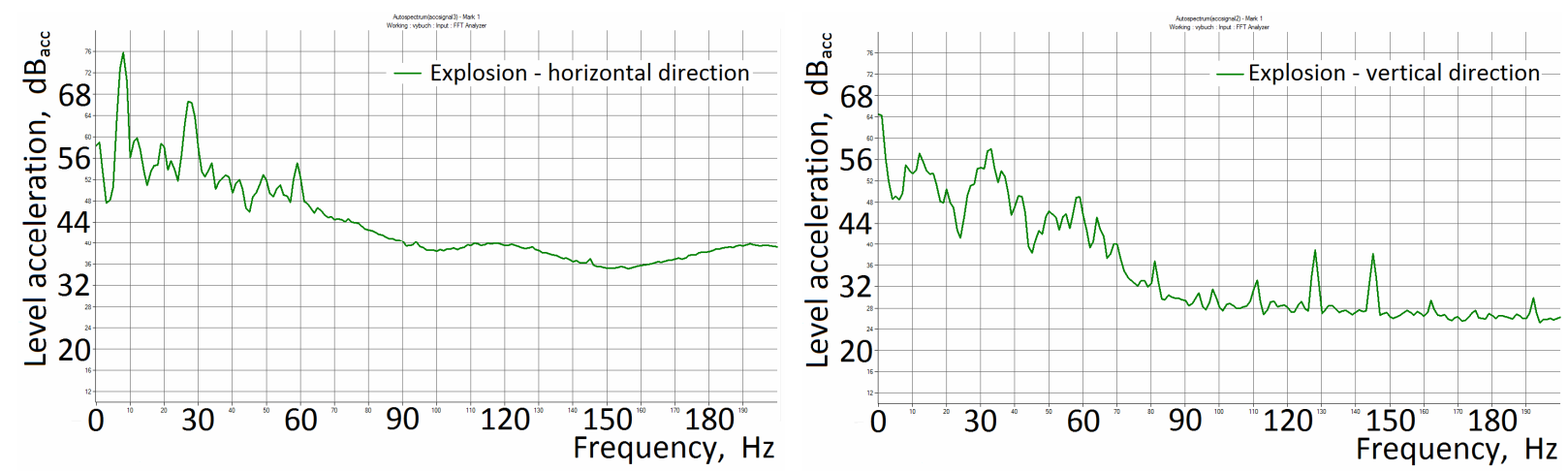

Figure 6: Frequency spectrum of a seismic shock in the horizontal direction (left) and vertical direction (right)

By means of the FFT analysis the levels of seismic acceleration (explosive) are determined in the measured locations. Due to the short duration of the seismic shock the highest possible averaging is used in order for the amplitudes of vibration, at the monitored frequencies, reached the correct value as closely as possible. The results of the FFT analysis of the seismic shock are given in fig. 6. The dominant amplitude of vibration is at $8 \mathrm{~Hz}$ in the horizontal direction, that is the direction of the seismic wave propagation. This frequency represents the natural frequency of the monitored structure (house). Therefore, according to relation (1) for the estimation of damping the duration of the dynamic excitation can be determined. On the 
other hand, with known response duration the modal damping properties of the structure can be determined. At this frequency, vibration amplitudes are significantly lower in the vertical direction which corresponds with the shear stress excitation (greatest in the horizontal direction). In general, the amplitudes of the structures vertical vibration are significantly lower. Comparing the right sides of fig. 5 and 6 the amplitude and frequency correlation can be seen, which documents the activities of a household appliance (possibly the refrigerator).

Comparison of the frequency spectra of the seismic shock and secondary vibrations (background) can be seen in fig. 7. In this comparison a noticeable increase in dynamic loading during the seismic event can be observed at lower frequencies. However this increase is not so significant as to negatively impact the structure of the building. This fact is solidified by the subjective feeling of the investigator and operator who were not able to feel the shock in the building. Graphs of the frequency analysis in units of vibration velocity are also shown In fig. 7, which can be a measure of seismic threat to buildings and industrial structures. It is important to remark that the time interval of the frequency analysis was one minute and so the energetic averaging coincides to this.
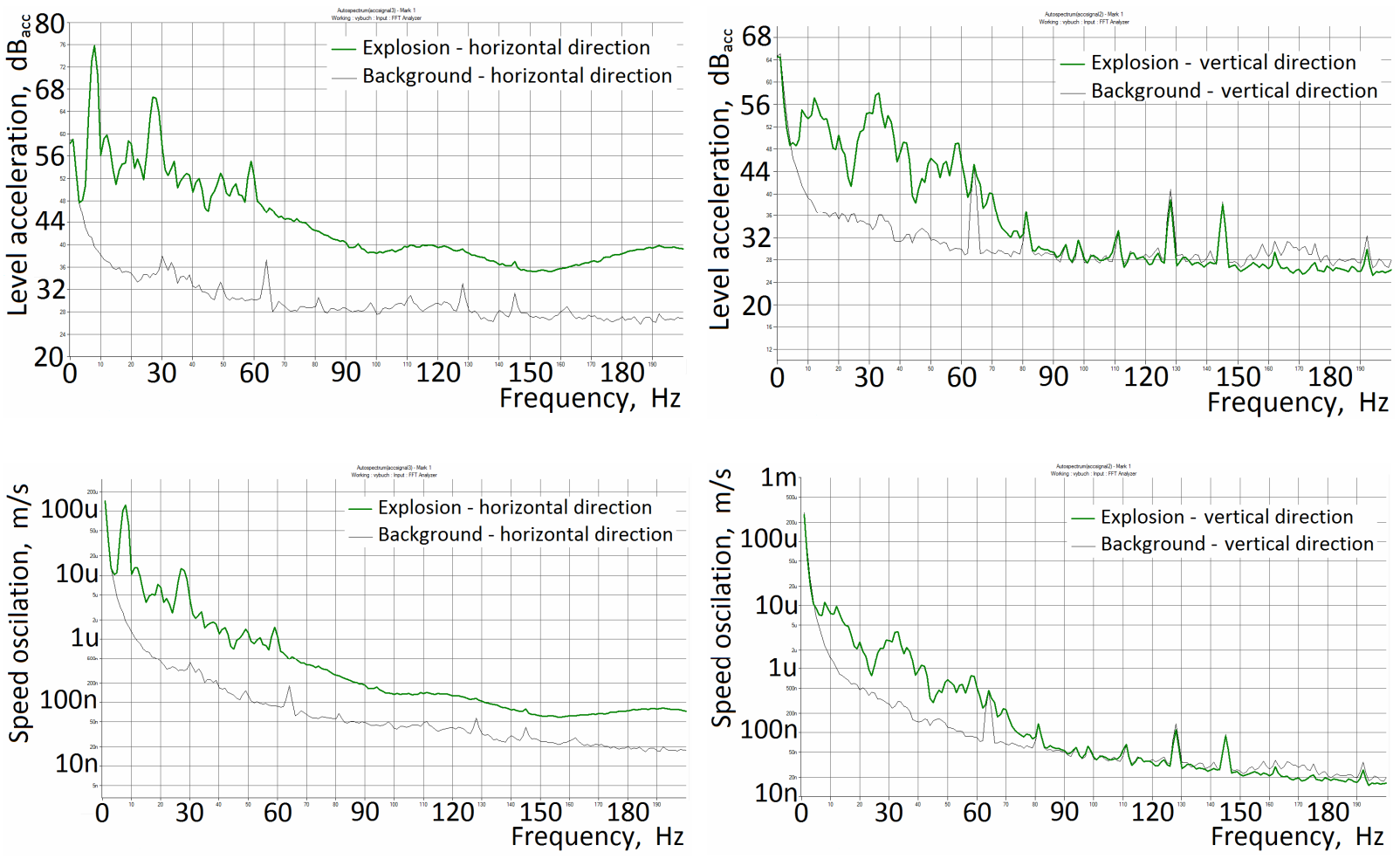

Figure 7: Comparison of the frequency spectra for an explosive shock and background in the horizontal direction (left) and vertical direction (right|)

\subsection{Time Character of an Explosive Shock (blast)}

With the frequency analysis, the time character of secondary dynamic loading in the monitored building was also measured with the time character of the seismic shock. The recorded time character serves further analysis of the dynamic loading in the structure. The time character of the seismic shock for both directions is seen in fig. 8. From the time character, it is possible to accurately determine the peak value of the building segments velocity where the sensor is placed. From fig. 8 (top) it is possible to state that the peak value in the vertical direction is not significant when compared to the peak value in the horizontal direction. The maximum segment acceleration of the building reached a value of $1.6 \mathrm{~m} / \mathrm{s}^{2}$, 
which gives a peak value of velocity of $v=31.84 \mathrm{~mm} / \mathrm{s}$. From fig. 8 it is possible to calculate the peak-to-peak value [10], whose velocity was $15.92 \mathrm{~mm} / \mathrm{s}$.

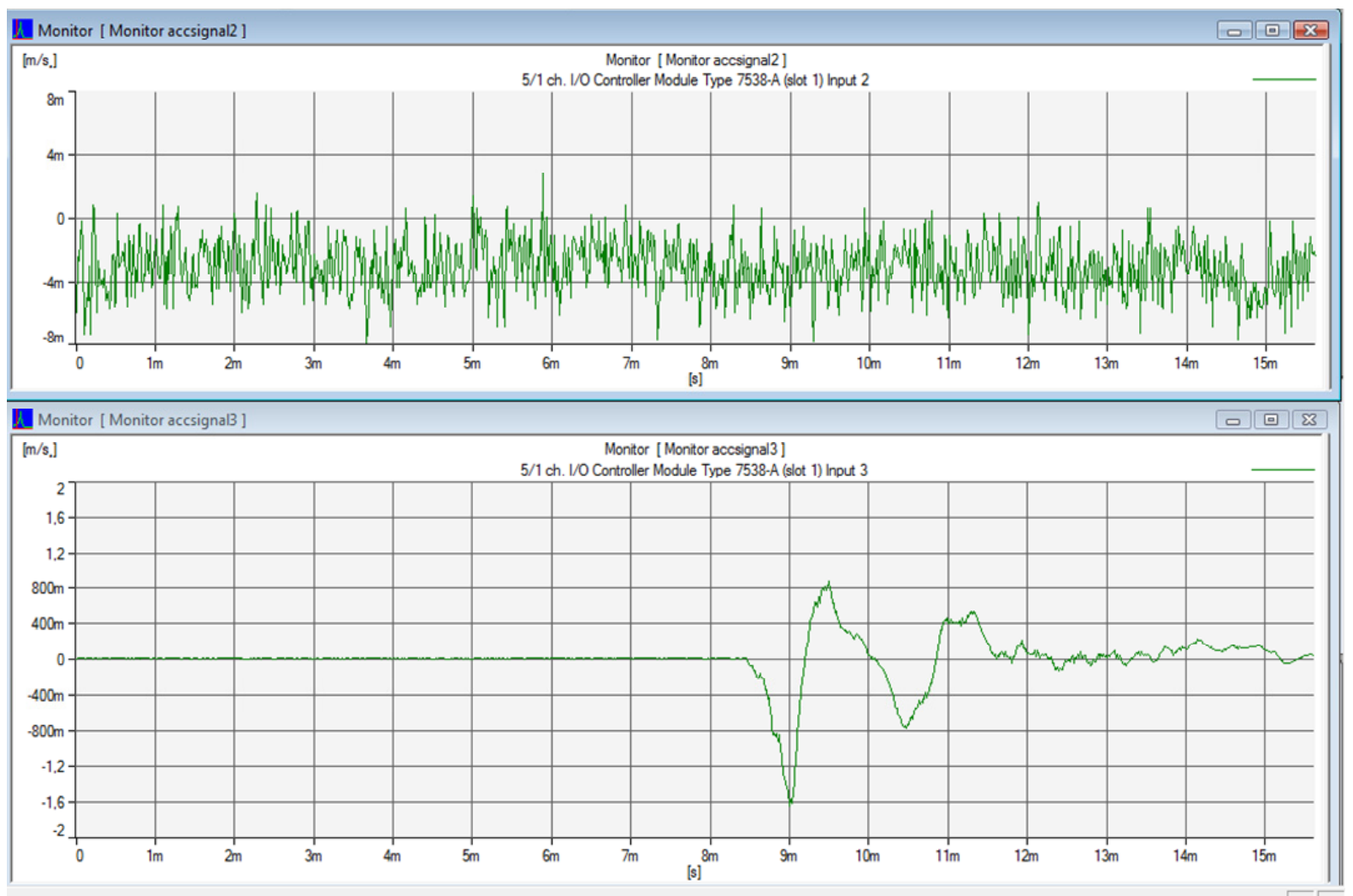

Figure 8: Time history of an explosive shock and background in the horizontal direction (bottom) and vertical direction (top)

\subsection{Evaluating the Effects of a Seismic Shock on the Given Building}

In terms of the standard ISO 4866, the monitored building can be categorized as a modern structure using relatively hard materials, which are connected in all directions and is relatively light with low damping factor. This category consists of the skeletal structure of the building as well as type of materials and load bearing. Buildings can be single level or multi leveled. All roofed types are included. This category contains older types of housing who's construction has been made with modern materials, constraints and damping.

ISO 4866 states that the foundation of the monitored building is categorized by A [8], which consist of these types of foundations: bound concrete rebar or steel piles and rigid concrete rebar footing and floor, on which the structure can be organized into the following types of ground: stones or hard rock, brittle rock, cemented or compacted sand, horizontally seated earth.

The type of analysis is obvious, if it is identified to which category the structure belongs in [8]. The variables, for this type of dynamic loading, are characterize as deterministic, and thus it is enough to use a simple analysis (effective value, peak value, peak-to-peak value, mean quadratic value).

Greater changes in cyclic stress cause a high risk of fatigue damage. In the given case, fatigue damage is not a factor because, for low levels of vibration which the analyzed source 
generated, it would require $10^{10}$ load cycles (blasts) [1]. Fatigue damage can be considered with high levels of response over a longer exposition duration.

A significant possibility of damage is related to the peak value of the structures segment velocity, whose value reaches a few hundred millimeters per second. In the given case, this value is significantly lower and the peak value of the velocity of the load bearing wall at the foundation reaches about $32 \mathrm{~mm} / \mathrm{s}$, which is almost at the beginning of the monitored range (see tab. 1 [8]) the value of peak-to-peak value is even smaller equal to only $16 \mathrm{~mm} / \mathrm{s}$. These values are not so great as to negatively affect the monitored building. This fact is confirmed by the subjective feeling of the investigator and operator which were present at the place if measurement during the seismic event.

\section{CONCLUSION}

In the measurement of seismic shocks (vibrations) it is very important, in the evaluation of seismic event on building and industrial structures, to correctly place the accelerometers. Each placement can cause significant deviation from the actual kinematic parameters of excited vibration. In determining the place of measurement it is important to respect also the height of the structure since vibrations tend to increase higher up in the structure. For the given object (house) the measurement point for the horizontal direction were chosen directly below the top of the buildings foundation on the main load bearing wall, which corresponded to the level of terrain outside, and was oriented perpendicular to the direction of high energy wave (toward the source). The sensor must always be mounted on load bearing elements of the structure or at least as close as possible. Measurement of vertical vibrations was performed near the load bearing wall, since this place better represents the structural integrity of the building than in the middle of the floor. The sensor was placed on a free standing steel cylinder placed horizontally on the floor. In no way should horizontal vibrations be measured in this way, doing such can result in more than $40 \%$ error [7, 15].

The International standard in [8] evaluates the level of damage in buildings by different categories. One of these categories is cosmetic damage, which is characterized by thin hairline cracks on the surface of a wall without finish (stucco), growth of existing cracks in drywall or on the surface of an unfinished wall (without stucco). Such damage, or any other form of damage, was not observed during the measurements.

\section{Acknowledgments}

This contribution was made possible by the project "Improving the safety of nuclear installations in seismic events" (ITMS project code: 26220220171), on the basis of support from the operational program for research and development financed by the European fund for regional development.

\section{REFERENCES}

[1] S. Ziaran, M. Musil, Action of seismic shocks on civil and industrial structures Part 1: General principles. Journal Physical Environmental Factors, $2^{\text {nd }}$ year, p. 93-100, October 2012.

[2] S.Žiaran, Research report V a K, Analysis of sources of mechanical vibration in water pumps, Bratislava 1992.

[3] S. Žiaran, Research report for woodworkers production center, Dynamic analysis of a single frame sawmill and the transfer of vibro-acoustic energy to its surroundings, Bratislava 2002. 
[4] S. Žiaran, Research report for the woodworkers production center, Dynamic analysis of a sawmill and recommendations for lowering the transfer of vibration to the surrounding areas, Bratislava 2003.

[5] S. Žiaran, Research report for PSL, Analysis of dynamic loading on industrial structures and foundations of machines DPR20, DPR26 and press LE 250 with recommendations for their vibro-isolation, Považská Bystrica, Bratislava 2005.

[6] S. Žiaran, Research report for NCHZ, Dynamic assessment of vibration for reactor R11, Bratislava 2001.

[7] S. Žiaran, Vibration and acoustics. Reducing vibration and noise in industry, Monograph, Published. STU Bratislava 2006.

[8] ISO 4866:2012 Mechanical vibration and shock. Vibration of buildings. Guidelines for the measurement of vibration and evaluation of their effects on buildings.

[9] K Medearis, Development of rational damage criteria for low rise structures subject to blasting vibrations. K. M. Assoc. Report, 1976.

[10] D.E. Siskind, M.S. Stagg, J.W. Kopp, C.H. Dowding, Report of Investigations No. RI. 8507, Structure response and damage produced by ground vibration from surface mine blasting, United States Bureau of Mines, 1980.

[11] Building Research Establishment (UK), Cracking in buildings. Digest No. 5, 1966 (reprinted 1975).

[12] S. Žiaran, M. Musil, Factors affecting internal air conditioning in building during seismic events, $23^{\text {rd }}$ conference on internal building climate, Contributions, High Tatras 2012, p. 47-52.

[13] ISO 2631-2:2003, Evaluation of human exposition to vibrations on the body. Part 2: continuous and shock induced vibration in buildings (from $1 \mathrm{~Hz}$ to $80 \mathrm{~Hz}$ )

[14] ISO 5348:1987, Mechanical vibration and shocks. Mechanical mounting of accelerometers.

[15] S. Žiaran, Technical diagnostics. Scientific monograph. In press, STU Bratislava 2013

[16] L. Soltes, M. Cekan, B. Hucko, Biomechanical model for seat comfort in automobiles. In Biomechanics 2012: International conference of the Polish Society of Biomechanics. Contributions, Bialystok, Poland, 2012, p. 265-266. 